\title{
AMBIENTES DE DESCOMPRESSÃO EM ESPAÇOS CORPORATIVOS
}

\author{
CARLUCCI, Marcelo \\ Senac Ribeirão Preto, e-mail: cep_arquitetos@hotmail.com \\ CARLUCCI DA SILVA, Luiza Helena \\ Senac Ribeirão Preto, e-mail: carlucciluiza@gmail.com \\ CARLUCCI PALAZZO, Fabiana \\ Senac Ribeirão Preto, e-mail: fabi.palazzo@gmail.com \\ CAVALINI LANÇA, Maria Izilda \\ Senac Ribeirão Preto, e-mail: mariaizildalanca@gmail.com \\ CEREZINE NEVES, Débora \\ Senac Ribeirão Preto, e-mail: de.neves@yahoo.com.br
}

\begin{abstract}
RESUMO
Este artigo é o trabalho final de Pós-Graduação em Design de Interiores, o qual já foi finalizado. Em nossos estudos, observamos que se tem tornado comum que grandes empresas invistam em espaços compartilhados e ambientes de descompressão visando enriquecer e fortalecer as atividades colaborativas e de convívio entre os funcionários. Com isso, partirmos do interesse de extrair questionamentos relativos às novas conformidades no design dos espaços de trabalho. Buscando inovação, melhor desempenho, produtividade e integração entre funcionários de áreas distintas, algumas empresas do mundo corporativo estão mudando a forma de pensar seus espaços. A atual geração está muito mais ligada à tecnologia, e suas relações sociais apresentam novos comportamentos, inclusive no meio de trabalho, por isso os espaços devem acompanhar essas mudanças. Nosso objetivo foi analisar as novas demandas e as mudanças que já aconteceram nos ambiente de trabalho $\mathrm{x}$ ambiente de convivência. Nossa metodologia foi análise acadêmica das novas demandas e estudos de casos recentes brasileiros. Como resultado, apresentamos algumas críticas aos casos analisados, e nossas contribuições foram novos caminhos a serem seguidos para melhora na relação: inovação no design versus novas demandas de trabalho.
\end{abstract}

Palavras-chave: Ambientes de Descompressão, Espaços Corporativos, Ambientes de Convivência.

\begin{abstract}
This article is the final work of Post-Graduation in Interior Design, which has already been finalized. In our studies, we have observed that it has become common for large companies to invest in shared spaces and decompression environments in order to enrich and strengthen the collaborative and social activities among employees. With this, we start from the interest of extracting questions regarding the new conformities in the design of the workspaces. Looking for innovation, better performance, productivity and integration among employees in different areas, some companies in the corporate world are changing the way they think about their spaces. Technology has advanced and people are very attached to this tool. The social relations of the present generations present new behaviors, even in the work environment, so the spaces must accompany these changes. Our objective was to analyze the new demands and the changes that have already happened in the work environment $x$ environment of coexistence. Our methodology was the academic analysis of the new demands and recent Brazilian real case
\end{abstract}

CARLUCCl, M.; CARLUCCI DA SILVA, L. H.; CARLUCCI, PALAZZO, F.; CAVALINI LANÇA, M. I.; CEREZINE NEVES, D. Ambientes de descompressão em espaços corporativos. In: SIMPÓSIO BRASILEIRO DE QUALIDADE DO PROJETO NO AMBIENTE CONSTRUÍDO, 6., 2019, Uberlândia. Anais... Uberlândia: PPGAU/FAUeD/UFU, 2019. p. 872-881. DOI https://doi.org/10.14393/sbqp19081. 
studies. Our results were some criticisms of the cases analyzed, and our contributions were proposed of new paths to be followed for improvements in the relation innovation in the design versus new demands of work.

Keywords: Decompression Environments, Corporate Spaces, Coexistence Environments.

\section{INTRODUÇÃO}

As pessoas mudaram, as empresas mudaram e a tecnologia também mudou. A busca por um plano de carreira está sendo aos poucos substituída pela ideia de um trabalho que atenda às ideologias e planos pessoais. Dentro disso, o design de interiores começa a propor espaços mais interativos, com mais cores, mais conforto, mais coletivo, menos individual e que propiciam mais encontros. Os ambientes de descompressão aparecem cada vez mais dentro dos espaços corporativos com a proposta de acompanhar essas mudanças. Mas será que esses novos espaços atendem às necessidades das novas gerações ou apenas encantam os olhos de quem está de fora?

\section{POR QUÊ A INTERAÇÃO É IMPORTANTE}

Algumas empresas vêm a alguns anos se preocupando em adequar seus espaços de interiores, por que entenderam que pode ser benéfico criar áreas de convivência dentro delas. A intenção é proporcionar aos funcionários um ambiente de descontração entre as horas de trabalho, em geral, com mobiliários, jogos e televisão. Esses espaços, em teoria, poderiam proporcionar interação entre funcionários de diferentes setores, ocasionando momentos de maior criatividade e produtividade.

Segundo Luciana Vaz (2010), para as empresas existe um desejo em buscar pessoas mais produtivas. E a estratégia por parte das grandes empresas para a realização desse desejo, é justamente investir nesses espaços de convivência. Inclusive, a visão de Andreza Abreu (2016), ainda reforça: "Esse investimento é como um círculo virtuoso: funcionários satisfeitos produzirão mais e com maior qualidade, e a organização aumentará sua rentabilidade" (ABREU, 2016 apud BOSA, 2017, p.9).

De acordo com Kaique Fernando Borges Bosa (2017, p.9), quando a empresa oferece condições de trabalho que se preocupem com o bem-estar do colaborador, os mesmos se sentirão mais saudáveis e satisfeitos com 0 ambiente de trabalho e, assim, reduzirão a fadiga, estresse e as doenças. Ainda segundo Bosa (2017), o espaço físico tem uma forte influência sobre as sensações humanas e a arquitetura pode ser um dos recursos mais importantes dentro das empresas.

Para entender se estas interações eram de fato eficazes, recorremos ao estudo apresentado no artigo de BenWaber, Magnolfi Jennifer e Greg Lindsay (2014, p.55-63) pela revista Harvard Business Review Brasil. Segundo a pesquisa, foram distribuídos crachás sociométricos' a funcionários de empresas de diversos setores, com intuito de obter informações sobre interação, comunicação e localização dessas pessoas no dia a dia de trabalho.

1 Crachá Sociométrico é um dispositivo no formato de um cartão que coleta amostras de dados relacionados à comunicação e o comportamento dos seus colaboradores, identificando em qual situação as pessoas trabalham melhor. Definição dada pela empresa Shelter It, disponível em: < http://www.shelterit.com.br/sobre-nos/ >. Acesso em: 24 de nov. 2018. 
O que se pode concluir através dos dados com os voluntários é que as interações cara a cara são muito importantes em um escritório: "Criar colisões - encontros casuais e interações espontâneas entre trabalhadores, tanto dentro como fora da organização - melhora o desempenho" (WABER; JENNIFER; LINDSAY, 2014, p.57). Além disso, a pesquisa também afirma que é importante projetar escritórios levando em consideração como o trabalho digital do século 21 acontece.

Podemos concluir que cada geração usa os espaços e também interage entre si de forma diferente, e que é preciso estudá-los quando formos projetar. Apesar de serem gerações que se comunicam muito através da tecnologia, a interação cara a cara se faz necessária para troca de ideias das quais estimulam a criatividade e aumentam a produtividade.

Para melhor entendimento, o tema "a melhoria da empresa através do design" foi aprofundado por Alex Sandy Pentland (PENTLAND, 2012 apud WABER; JENNIFER; LINDSAY, 2014, p.58), que também fez um estudo em uma série de empresas, com o intuito de descobrir, através do uso de crachás sociométricos, os locais que os funcionários frequentavam e com quem falavam. Os resultados eram anônimos, não foram divulgados aos empregadores e não mediam o conteúdo da interação. Ao final desta pesquisa, ele pode concluir que existem três elementos-chaves em uma comunicação:

[...] "exploração (interação com pessoas de vários grupos sociais), engajamento (interação com pessoas dentro de seu grupo social, em doses razoavelmente iguais) e energia (interação com mais pessoas em geral)" (PENTLAND, 2012 apud WABER; JENNIFER; LINDSAY, 2014, p. 58).

Ele pode entender que espaços projetados e pensados para serem convidativos a estas interações são mais propensos a ocasionar colisões entre os funcionários. E os dados comumente mostram que essas colisões trazem resultados positivos. Também que cada empresa projeta espaços para favorecer um tipo de atividade. No caso de uma central de atendimento, ampliar a sala de descanso foi benéfico, pois proporcionou momentos de interação entre os colegas fora do horário das ligações telefônicas e ocasionou que o conhecimento circulasse dentro do grupo (PENTLAND, 2012 apud WABER; JENNIFER; LINDSAY, 2014, p.58).

Ainda segundo a pesquisa, já no caso de uma empresa farmacêutica, segundo dados dos crachás sociométricos, proporcionar a exploração seria a melhor opção, pois os melhores resultados eram obtidos quando os funcionários tinham interações com colegas de equipes diferentes das suas. Então, para aumentar esse tipo de colisão, a solução foi alterar a disposição das máquinas de café. Antes, a proporção era de uma máquina de café para cada seis pessoas, que tinham o costume de utilizar sempre as mesmas máquinas. Ou seja, os funcionários se relacionavam sempre com as mesmas pessoas. Agora, as máquinas de café são maiores, mas apenas uma para cada 120 pessoas, proporcionando mais interações. Com essas alterações, as vendas aumentaram $20 \%$.

O estudo conclui: "Os gestores podem ser tentados a simplesmente construir grandes espaços sociais e esperar grandes resultados, mas as coisas não são 
tão simples assim. As empresas precisam saber o que pretendem conseguir (...) antes de mudar um espaço" (WABER; JENNIFER; LINDSAY, 2014, p.60).

Concluindo, podemos entender que através de um projeto de design de interiores é possível ocasionar diferentes tipos de interações dentro de uma empresa, sendo elas com pessoas de um mesmo grupo de trabalho ou não. $E$ é muito importante também entender o funcionamento da empresa e seus funcionários para saber quais são as interações ideais e, somente a partir desses resultados, pensar nas modificações dos espaços.

\section{COWORKING}

Incorporamos este capítulo sobre Coworking por entendermos que este tipo de ambiente de trabalho também apresenta discussões sobre a importância das interações "cara a cara" e com pessoas de diferentes áreas no âmbito profissional. Segundo Julia Okubo (2018):

Coworking (...) trata-se de um espaço onde profissionais liberais ou micro e pequenos empreendedores podem instalar suas empresas. Essa estrutura foi planejada para incentivar 0 networking, em um contexto de inovação e ascensão dos fluxos de informações digitais.

O estudo descreve como desde 2005 os usuários do ramo da tecnologia e criação buscam por locais de trabalho que fuja da ideia comum de escritório. Uma vez que a Tecnologia da Informação, em geral, se adapta as necessidades dos seus usuários, esses passaram a esperar esta adaptabilidade também nos espaços de trabalho (WABER; JENNIFER; LINDSAY, 2014, p.61).

De acordo com Ben Waber, Magnolfi Jennifer e Greg Lindsay (2014), os coworkings surgiram compostos por pessoas de diferentes áreas de trabalho, acessíveis a qualquer um e por vezes, gratuitos. Além disso, não foram previamente pensados por designers, aconteceram de forma espontânea. Nesta configuração, os espaços iriam propor interação social, energia, proximidade física, ou seja, ações de exploração, que como explicado no capítulo anterior aumentam a criatividade.

Esses espaços aparecem como uma opção para esse novo modelo de negócio: os empreendedores compartilham a estrutura física e de rede, diminuindo custos e aumentando sua interação com os outros profissionais (OKUBO, 2018, p.4).

Ainda segundo o artigo de Ben Waber, Magnolfi Jennifer e Greg Lindsay pela revista Harvard Business Review Brasil (2014, p.55-63), é preciso considerar que segundo o estudo do grupo Emergent Research, dois terços do conhecimento ocorrem fora do escritório. Entende-se que as ferramentas digitais podem facilitar a comunicação, ou seja, ter em um mesmo local mais ideias. No entanto, os estudos mostram que quanto maior a distância física entre os grupos de trabalho, menores são as interações. Isso prova que a interação digital não substitui à física, apenas a complementa.

Jennifer Magnolfi (WABER; JENNIFER; LINDSAY, 2014, p.61) afirma ter entendido que os coworkings começaram a ser mais procurados justamente pelos benefícios que as interações poderiam proporcionar. Apesar de ter surgido da informalidade, esse tipo de espaço cresceu e inclusive empresas comuns passaram a abrir uma parte de seus escritórios para funcionarem como 
coworkings. Como exemplos, o artigo aponta a nova sede da Amazon em Seattle, empresa que proporcionou um dos andares da empresa para funcionar como coworking, e até mesmo a Airbnb que oferece em seu site uma das salas de reunião da empresa para uso gratuito de qualquer pessoa.

Podemos concluir que esses espaços são procurados no intuito de fazer contato com outras pessoas, ter companhias no trabalho, trocar informações e também dividir os gastos de um negócio. O fato de o coworking ter surgido de forma espontânea mostra que estas interações sociais no trabalho de fato são vistas como proporcionadoras de situações benéficas. E, também que as grandes empresas já vêm notando os benefícios desses locais e incorporando em seus espaços.

\title{
4 GERAÇÃO Y - MILLENIALS (GERAÇÃO DA INTERNET)
}

Como já discutimos anteriormente, é preciso entender o comportamento e o contexto histórico de uma geração para compreender o que buscam em um espaço de trabalho.

Julia Okubo (2018, p.12-16) nos relembra importantes momentos na história, como a Primeira e a Segunda Revolução Industrial, que implementaram máquinas no ambiente de trabalho, produção em série, exploração máxima de recursos e tentativas de recuperação pós períodos de guerra, fatores que influenciam na forma de lidar com o trabalho. Estes períodos históricos representavam diferentes relações entre chefe e trabalhador. Atualmente, valoriza-se a ciência, informação e técnica, e o conhecimento se sobressai, o que influencia na forma de lidar com o trabalho (OKUBO, 2018, p.12). Pode-se entender que o contexto histórico, ou seja, a economia, as relações pessoais, a tecnologia, o ensino e outras questões de uma geração influenciam muito no comportamento dentro do ambiente de trabalho. Esta questão pode ser mais bem entendida pela fala de Ascenço:

\begin{abstract}
Os jovens Y são fruto de um cenário econômico mais estável, com o desenvolvimento tecnológico constante e mais conectividade. Graças a esses pontos apresentados acima, eles tiveram mais acesso à informação e a educação formal, especialmente ensino superior, diferentemente de seus pais. Mudou-se também a maneira de como enxergar sua carreira e trajetória profissional. Ao contrário de nossos pais (média de 55 anos hoje), a geração Y não separa tanto a sua vida pessoal da profissional. Esses dois lados costumam estar sempre envolvidos e hoje acabamos encontrando muitos jovens sobrecarregados com a rotina e responsabilidade de ambos os lados (ASCENÇO, 2017, p. 72 apud OKUBO, 2018, p.12).
\end{abstract}

Também é importante notar que há uma maior complexidade na forma em que a geração Y lida com o mercado de trabalho, pois considera importantes questões como motivação, identificação com os valores da empresa e satisfação pessoal (OKUBO, 2018, p.12).

A pesquisa realizada por Andreia Martins sobre a Geração Y também fomenta esta questão:

[...] os jovens procuram ambientes organizacionais agradáveis, com remuneração justa e também tempo livre para que possam se dedicar a hobbies e a família. Assim, sugere-se que 
as organizações utilizem estratégias tais como assessment, programas de trainee, estabelecimento de metas e feedbacks para melhor entender essa geração (MARTINS, 2016, p. 8).

Podemos concluir que os estudos e vivências da geração $Y$ os tornaram profissionais que procuram por satisfação e motivação no trabalho, ou seja, é possível compreender por que as empresas buscam se atualizar e criar espaços de trabalho que representem esta geração, com inclusive áreas de descompressão.

Também é importante acrescentar que a sociedade tem sofrido grandes mudanças, uma delas é o aumento da expectativa de vida: isso significa maior preocupação com a saúde e qualidade de vida das pessoas, exigindo novos hábitos comportamentais em todos os aspectos, incluindo o ambiente de trabalho (LIMONGI-FRANÇA, 2004, p.22).

\section{ESTUDOS DE CASOS BRASILEIROS}

A seguir, apresentaremos dois estudos de casos de ambientes de convivência em empresas com sede no Brasil. Em seguida, discutiremos esses espaços através de uma análise conjunta.

\subsection{Sede da empresa Mercado Livre}

A nova sede do Mercado Livre localiza-se em Osasco, na Grande São Paulo. O escritório responsável pelo projeto foi o Athié Wohnrath em parceria com o escritório argentino Estudio Elia/ Irastorza (EEI). A análise foi feita por meio das imagens e descrições disponíveis no site Galeria da Arquitetura.

De acordo com o site, o estabelecimento conta com os seguintes espaços internos: cafeteria, 140 salas de reunião, 11 salas de treinamento, auditório com 200 lugares, arquibancada, eventos internos, biblioteca, espaços de descanso, restaurante e também com uma área de esportes e lazer.

A arquiteta argentina Milagros Irastorza, do Estudio Elia / Irastorza (EEI), explica: "O Mercado Livre dá muita importância à versatilidade de espaços. A ideia é a interação entre os funcionários, e que seja desenvolvido o senso de comunidade".

A Figura 1 mostra um dos espaços de convivência da empresa. A partir dela é possível fazer uma leitura desse ambiente: o chão possui textura de madeira que traz conforto, o mobiliário é composto por mesas, cadeiras, poltronas e vasos com vegetação, as cadeiras nas cores amarela e verde trazem mais vida ao ambiente que harmoniza-se perfeitamente com o caráter industrial do prédio.

O local estimula a interação entre os colaboradores, fazendo com que estes troquem ideias e experiências profissionais. Ou seja, esse espaço não é necessariamente só para o lazer, mas também serve como um local de trabalho descontraído. No entanto, pode-se observar na imagem a falta de privacidade, pois ele é todo aberto e coletivo e no entorno ficam funcionários trabalhando em mesas de trabalho, e isso pode fazer com que os funcionários não se sintam totalmente à vontade para descansar e relaxar. 


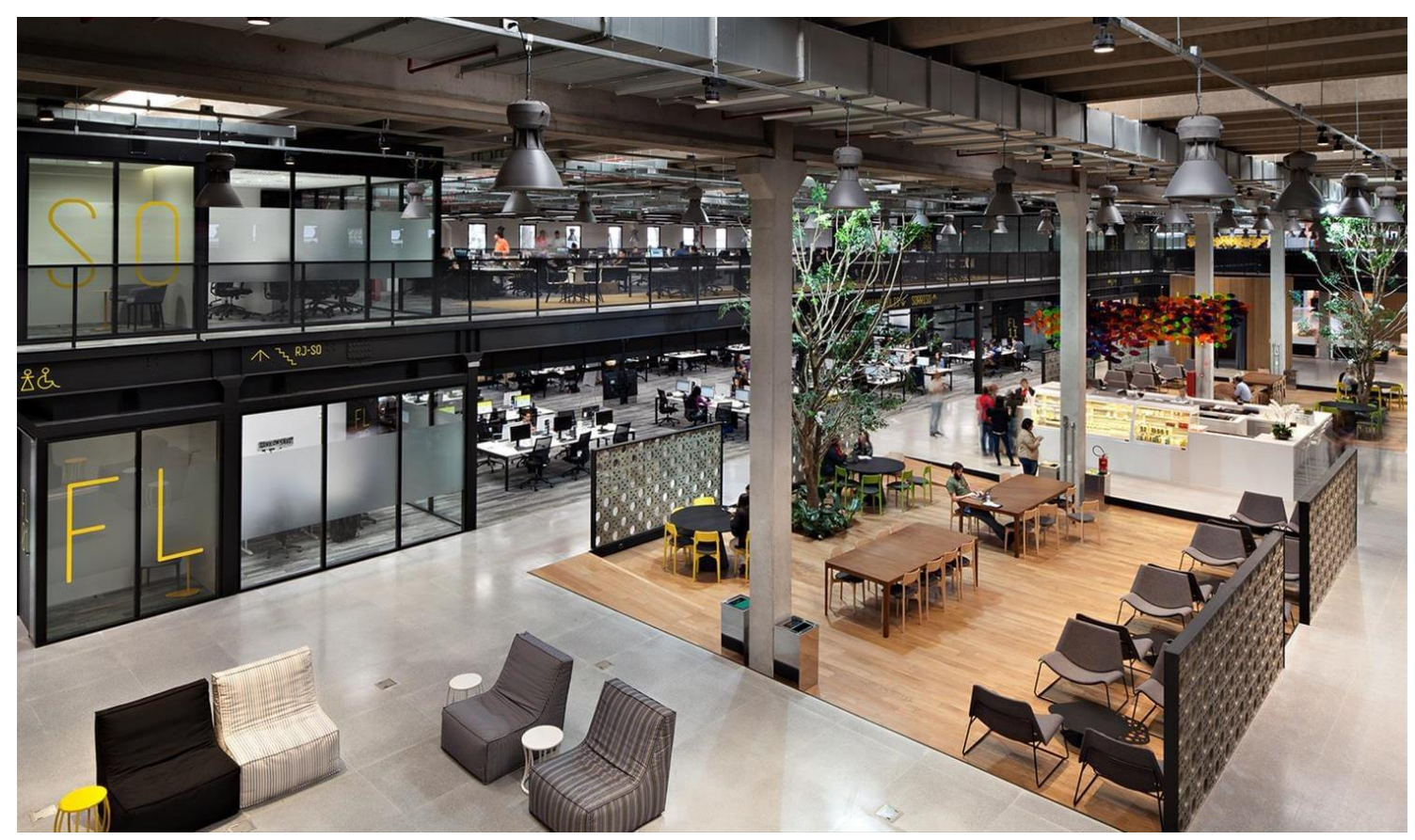

Figura 1 - Ambiente de convivência Mercado Livre -

Fonte: Galeria da Arquitetura. Disponível em: <https://www.galeriadaarquitetura.com.br/projeto/athiewohnrath_estudio-elia-irastorza-eei_/nova-sede-do-mercado-livre-no-brasil/3475>. Acesso em: 24 nov. 2018.

\subsection{Lounge da empresa Bauducco}

O projeto do lounge da empresa Bauducco (Figura 2) é de autoria do escritório Suite Arquitetos, e a maior preocupação dos arquitetos é que o espaço comporte o fluxo diário da empresa que conta com 300 funcionários.

De acordo com a entrevista da arquiteta Daniela Frugivele, no site Galeria da Arquitetura, a ideia do projeto foi de criar um local onde os funcionários pudessem repousar e descontrair, fazendo com que se sintam em casa. Como vemos na figura abaixo, o espaço é totalmente livre. A partir do layout foi possível criar diferentes ambientações.

No entanto, estas questões nos fazem refletir se os espaços são de fato utilizados pelos funcionários como a empresa gostaria, pois por mais que o objetivo seja a descontração, ambientes de trabalho exigem seriedade e formalidade em frente aos chefes e até mesmo aos colegas de trabalho. Perguntamo-nos se os funcionários se sentem à vontade para deitar em arquibancadas e se acomodarem nestes espaços que remetem à sala de nossas casas.

O lounge é composto por uma arquibancada que é área de jogos, uma parte reservada para meditação e yoga, um carrinho que funciona como uma biblioteca itinerante, mesa de piquenique, sofás, pufes, poltronas, e mesas de centro e dentre outros elementos que compõem o mobiliário.

De acordo com arquiteta Daniela Frugiele, eles buscaram trabalhar com materiais que tivessem uma manutenção prática e simples e para ter mais resistência alguns materiais não receberam acabamentos e outros foram pintados, trazendo uma característica forte ao layout. A paleta de cores vermelha e amarela representa a marca Bauducco acrescida de um mix da cor azul para transmitir sensação de paz e trazer suavidade. 


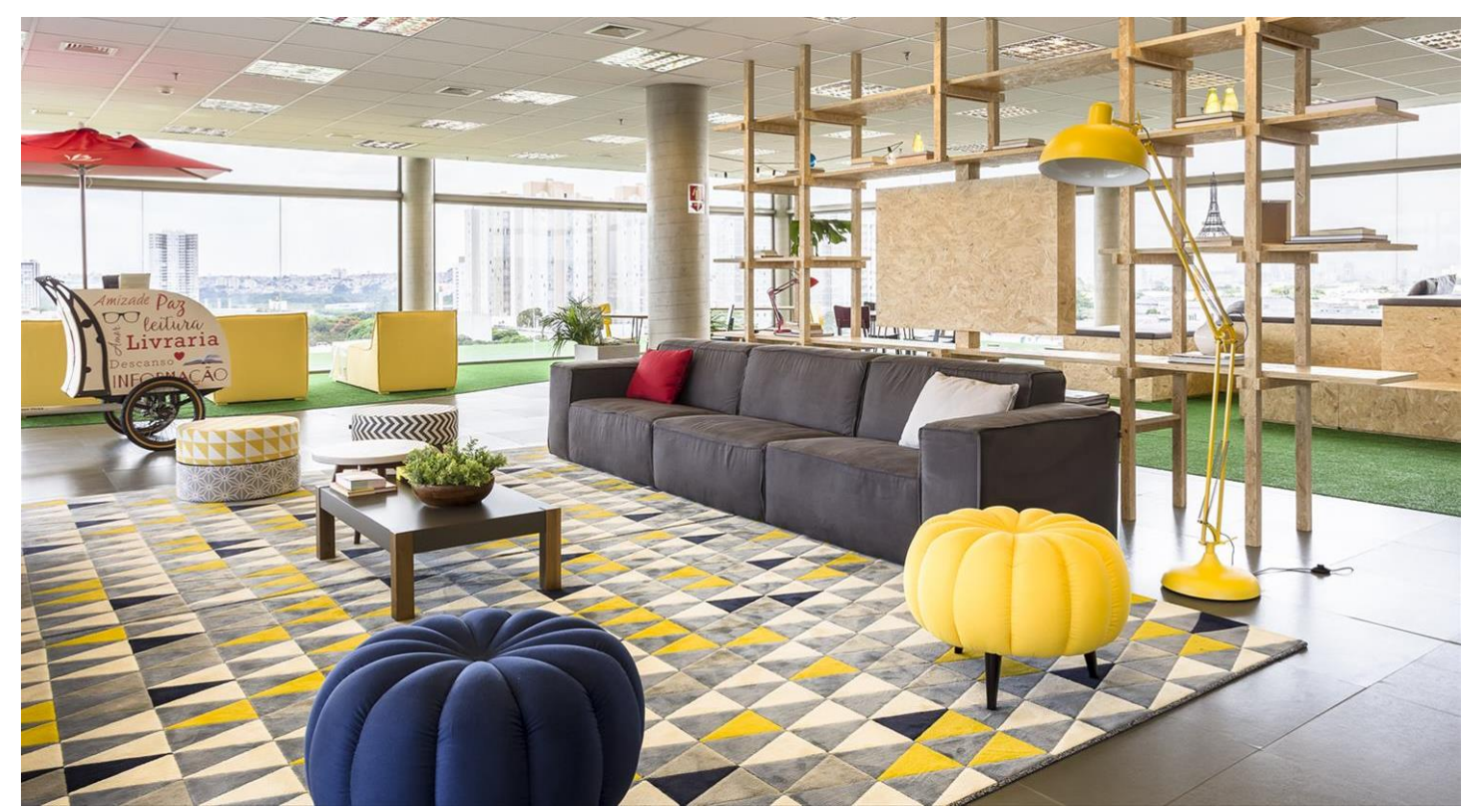

Figura 2 - Louge da empresa Bauducco -

Fonte: Galeria da Arquitetura. Disponível em: <https://www.galeriadaarquitetura.com.br/projeto/suitearquitetos_/lounge-bauducco/3985>. Acesso em: 24 nov. 2018.

Diferente da sede do Mercado Livre, o espaço de convivência da Bauducco é mais privado, pois a empresa tem um espaço próprio para isso, e não deixando de ser um espaço de descanso coletivo, estimulando a interação entre os funcionários. Em relação ao outro espaço de convivência visto acima, esse proporciona um momento de descanso mais relaxante, porém como podemos ver na imagem e na descrição é um espaço lúdico.

\subsection{Análise dos dois estudos de caso}

As duas empresas estudadas são de áreas diferentes: o Mercado Livre é de tecnologia de comércio eletrônico e a Bauducco é da área alimentícia. Porém, as duas oferecem espaços de convivência e descanso aos seus funcionários, e esses espaços compartilham características em comum, sendo o objetivo principal estimular a interação e troca de experiências entre os funcionários e oferecer um espaço de descompressão. Compartilham também características no design de interiores, como cores, texturas e tipos de mobiliários.

Observa-se o uso de cores vibrantes se contrastando com tons neutros: o cinza está presente nos dois espaços e, de acordo com Filipe Gustavo Leão (2017), essa cor representa a neutralidade, confiança, segurança e monotonia; e o amarelo e o vermelho que representam a energia, recreação e força, formando um equilíbrio de tonalidades. Estas cores vibrantes comportam nesses ambientes, pois o objetivo é justamente passar a ideia de descontração.

São usados tapetes junto com o layout que criam diferentes ambientações. Também são espaços totalmente livres, e os mobiliários dos dois são compostos por sofás, poltronas, pufes, chaises, mesas de centro e tapetes. 
Todas essas características formam uma mesma linguagem no design desses espaços de convivência.

É importante lembrar que estes ambientes estão inseridos em locais de trabalho que requerem seriedade. Como apresentado pelas pesquisas, as atuais gerações de fato buscam por espaços mais descontraídos. No entanto, também se concluiu que antes da concepção desses espaços, é preciso estudar a empresa e seus funcionários para melhor entender qual o layout ideal, não basta colocar pufes e sofás.

Por isso, entendemos que para que esses espaços tragam benefícios para as empresas e seus funcionários, é preciso ouvi-los. Perguntamo-nos se estes funcionários pudessem escolher entre ter tempo de utilizar esses espaços de descompressão dentro das empresas ou ter tempo livre fora delas, por exemplo, em suas casas, o que prefeririam?

Entendemos que a criação desses espaços é muito interessante, e que podem de fato ocasionar interação e relaxamento. No entanto, por vezes a ideia se perde com o exagero de se parecerem com a "sala de nossas casas" e também com a criação de muitos ambientes. Faz-nos refletir se espaços menores ou mesmo modulares não proporcionam o mesmo benefício.

\section{CONCLUSÕES}

Neste artigo analisamos como os ambientes de descompressão atuam dentro dos espaços corporativos. Visando o avanço tecnológico e mudanças que afetaram tanto a forma de se relacionarem e de trabalhar das pessoas, entendemos que existem alguns questionamentos a serem pensados sobre a concepção destes ambientes de descompressão a partir do design de interiores.

Sendo assim, concluímos que estes ambientes são importantes e estão se tornando cada vez mais atrativos dentro das empresas. Por, principalmente, realizarem colisões estratégicas entre os funcionários, mas também introduzirem horas de descontração em meio às de trabalho, e com isso proporcionarem maior produtividade aos funcionários.

Concluímos também que a partir dos estudos de casos analisados, existe uma grande similaridade entre esses espaços: mesmas cores, mesmos móveis, texturas, mesma intenção de aconchego. Porém, é necessário analisar sempre o real uso desses espaços, para que não extrapolem sua função, ficando mais visíveis do que utilitários.

\section{REFERÊNCIAS}

OKUBO, J. Coworking: um modelo que representa a relação da sociedade atual com o trabalho. 2018. 65 f. Trabalho de conclusão de curso (bacharelado - Comunicação Social-Relações Públicas) - Universidade Estadual Paulista Júlio de Mesquita Filho, Faculdade de Arquitetura, Artes e Comunicação, 2018. Disponível em: <http://hdl.handle.net/11449/156485>.

MARTINS, A. Inquietude jovem: geração y e o mercado de trabalho. 2016. 1

CD. Trabalho de conclusão de curso (bacharelado - Relações Públicas) Universidade Estadual Paulista Júlio de Mesquita Filho, Faculdade de Arquitetura, Artes e Comunicação, 2016. 
WABER, B.; JENNIFER, M.; LINDSAY, G. Espaços de trabalho que movem pessoas. Harvard Business Review - Brasil, São Paulo, v.92 n.10, p.55-63, out.2014.

MARQUEZ, A. Trabalho, doce lar. Disponível em:

<https://www.galeriadaarquitetura.com.br/projeto/athie-wohnrath_estudioelia-irastorza-eei_/nova-sede-do-mercado-livre-no-brasil/3475>. Acesso em: 7 nov. 2018.

LIMONGI-FRANÇA, A. C. Qualidade de vida no trabalho - QVT: Conceitos e práticas nas empresas da sociedade pós-industrial. $2^{a}$ Edição. São Paulo: Editora Atlas S.A., 2004.

BOSA, K. F. B. Arquitetura corporativa: qualidade de vida no trabalho. 2017. Trabalho de conclusão de curso (bacharelado - Arquitetura e Urbanismo) Unicesumar - Centro universitário de Maringá, Centro de Ciências Exatas, Tecnológicas e Agrárias, Curso de Graduação em Arquitetura e Urbanismo. 2017. Disponível em:

<http://rdu.unicesumar.edu.br/bitstream/handle/123456789/41 1/Kaique\%20Fer nando\%20Borges\%20Bosa.pdf? sequence=1 \&isAllowed=y>.

VAZ, L. Qualidade de vida na empresa: conceitos e práticas em uso (no segmento do comércio de bens e serviços na cidade de São Paulo). 2010. Dissertação de Mestrado (Educação Física) - Universidade Estadual De Campinas, Faculdade De Educação Física. 2010. Disponível em: <http://repositorio.unicamp.br/bitstream/REPOSIP/274737/1/Vaz_Luciana_M.pd $f>$.

LEÃO, F. G. Psicologia das cores no design de interiores. 2017. Teresina. Disponível em: <https://designculture.com.br/autor/filipe-gustavo-leao>. Acesso em: 24 nov. 2018. 